\title{
Characterization of the Electrically Evoked Release of Substance P from Dorsal Root Ganglion Neurons: Methods and Dihydropyridine Sensitivity
}

\author{
George G. Holz IV, Kathleen Dunlap, and Richard M. Kream' \\ Departments of Physiology and 'Anesthesiology, Tufts University School of Medicine and New England Medical Center, \\ Boston, Massachusetts 02111
}

The mechanism by which dihydropyridines (DHPs) modulate the electrically evoked or $\mathrm{KCl}$-induced release of substance $P$ (SP) from embryonic chick dorsal root ganglion (DRG) neurons was investigated in the present study. The release of SP, as measured by radioimmunoassay (RIA), was characterized in terms of its dependence on extracellular calcium ion, its stimulus-response relationship, its sensitivity to the calcium-channel blocker omega conus toxin ( $\omega$-CgTx), and its modulation by the DHPs Bay K 8644 and nifedipine. Here it is reported that $\omega$ - $\mathrm{CgTx}(1 \mu \mathrm{M})$ blocked the electrically evoked release of SP. In contrast, the calcium-channel agonist Bay K $8644(5 \mu \mathrm{M})$ facilitated the release of SP (by $45 \%$ ), whereas the calcium-channel antagonist nifedipine (5 $\mu \mathrm{M})$ was without effect. When the release of SP was triggered by depolarization of cultures with $60 \mathrm{~mm} \mathrm{KCl}$, the actions of the DHPs became much more pronounced. Under these conditions, Bay K 8644 facilitated (by 115\%), whereas nifedipine inhibited (by $58 \%$ ), peptide secretion. Voltage-clamp analysis of DRG cell calcium currents demonstrated that these actions of $\omega-\mathrm{CgTx}$, Bay $\mathrm{K} 8644$, and nifedipine are explicable in terms of their effects on the slowly inactivating (L-type) calcium current. On the basis of these findings, it is suggested that the SP release mechanism exhibits DHP sensitivity due to the involvement of L-type calcium channels in the neurosecretory process. This model predicts that the voltage and time-dependent antagonist actions of nifedipine are sufficient to explain its failure to inhibit the electrically evoked release of SP.

Substance P (SP) is a tachykinin neuropeptide synthesized and secreted by finely myelinated and unmyelinated primary afferent neurons (Pernow, 1983a). Subsequent to its isolation, purification, and chemical characterization by Chang and Leeman in 1970, attention focused on the role of SP as an excitatory transmitter or modulator at spinal terminations of primary afferent nociceptors (Otsuka and Konishi, 1976; Henry, 1977, 1982; Jessel and Iversen, 1977; Gamse et al., 1979; Nicoll et al., 1980; Yaksh et al., 1980). More recently, attention has also been fo-

\footnotetext{
Received Dec. 9, 1986; revised May 26, 1987; accepted July 28, 1987.

This work was supported by grants to K.D. from the NIH (NS 16438), the Klingenstein Fund, and the American Heart Association (with funds contributed, in part, by the Massachusetts affiliate), and to R.M.K. from NIDA (DA 04128) and the New England Medical Center (BRSG 19-807419).

Correspondence should be addressed to Dr. George G. Holz IV, Department of Physiology, Tufts University School of Medicine, 136 Harrison Avenue, Boston, MA 02111.

Copyright (C) 1988 Society for Neuroscience $0270-6474 / 88 / 020463-09 \$ 02.00 / 0$
}

cused on the peripheral terminations of primary afferent neurons, where released SP is implicated as a mediator of neurogenic inflammation (Pernow, 1983b, 1985), and as a modulator of immune system function (Goetzl et al., 1985; Payan and Goetzl, 1985). Despite the apparent importance of these diverse biological actions of SP, very little is known regarding cellular processes that regulate its release.

In an attempt to address this question, we have studied the mechanism by which depolarization induces the release of SP from embryonic chick dorsal root ganglion (DRG) neurons. It was previously reported that these primary afferent neurons synthesize and secrete SP when grown in dissociated cell culture (Mudge, 1979, 1981; Mudge et al., 1979). These earlier studies examined the mechanism by which depolarizing concentrations of $\mathrm{KCl}$ induce peptide secretion. In the present paper we characterize the electrically evoked release of SP, as measured by RIA and as authenticated by high-pressure liquid chromatography (HPLC). In addition, we have begun to characterize the type of calcium channel(s) through which calcium enters to trigger secretion.

Recent electrophysiological studies have determined that 3 types of depolarization-induced calcium current may be recorded from the soma membrane of DRG neurons (Nowycky et al., 1985a). These 3 currents presumably reflect calcium influx through 3 distinct subtypes of voltage-dependent calcium channel. Current flow through one of these, termed the L-type channel, is selectively inhibited by the dihydropyridine (DHP) calcium-channel antagonist nifedipine (Rane et al., 1987), and facilitated by the DHP calcium-channel agonist Bay K 8644 (Nowycky et al., 1985a, b). Moreover, Perney et al. (1986) reported that antagonist DHPs block the $\mathrm{KCl}$-induced release of SP from neonate rat DRG cell cultures. In order to more fully investigate the potential role of L-type calcium channels in neurosecretory processes, we have examined whether DIIPs also modulate the electrically evoked release of SP.

We now report that Bay K 8644 facilitated both the electrically evoked and $\mathrm{KCl}$-induced release of SP. In contrast, nifedipine failed to inhibit release evoked by electrical-field stimulation, but reduced peptide secretion induced by $60 \mathrm{~mm} \mathrm{KCl}$. These findings are interpreted in terms of the voltage and time-dependent actions of DHPs on L-type calcium channels, as assessed by electrophysiological recordings from these same cells. A model is proposed whereby neuropeptide secretion is triggered by calcium influx through L-type calcium channels located at release sites on primary afferent nerve terminals. This model predicts that the voltage and time-dependent antagonist actions 
A
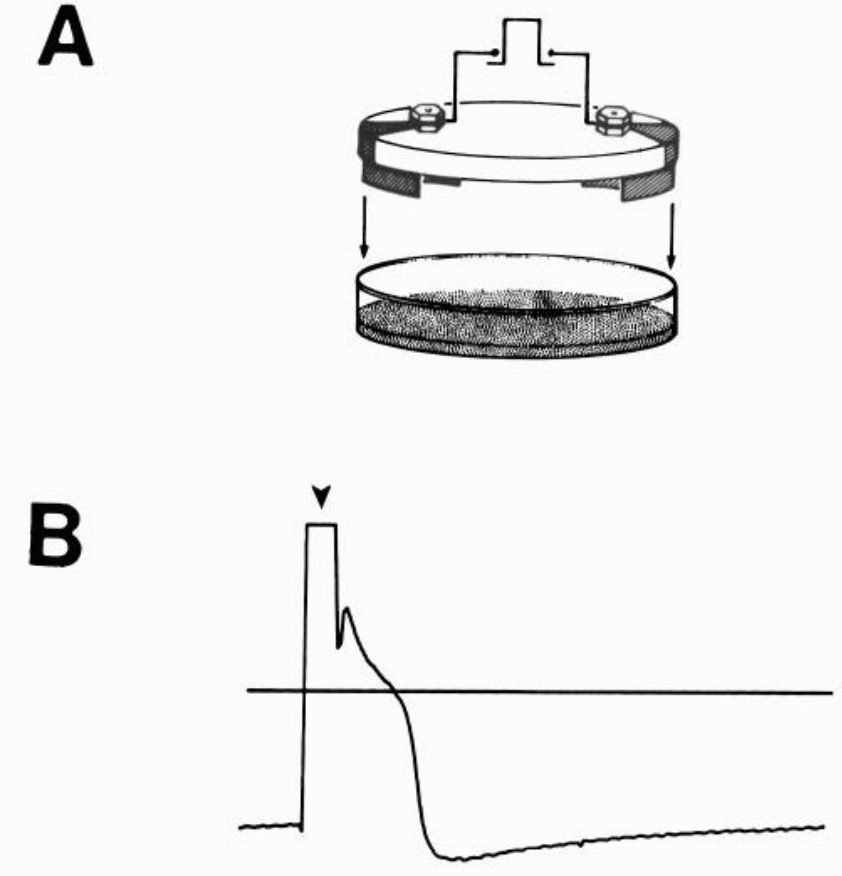

Figure 1. Electrical field stimulation of DRG cell cultures. $A$, Design of the stimulation chamber. Bipolar platinum steel electrodes are inserted into the $60 \mathrm{~mm}$ tissue culture dish so that they contact the solution bathing the cells. Note that when inserted, each electrode occupies one-third of the inner circumference of the dish. $B, C$, Action potentials (note different time scales) recorded from the same DRG neuron in response to electrical field stimulation (square-wave DC pulses, $110 \mathrm{~V}, 3 \mathrm{msec}$ duration). A single action potential is illustrated in $B$ (arrowhead indicates stimulus artifact), whereas a train of action potentials evoked by stimulation at $25 \mathrm{~Hz}$ is illustrated in $C$. The resting potential was $-58 \mathrm{mV}$. The horizontal line through the spikes indicates the zero potential determined after withdrawing the electrode from the cell. The recording solution consisted of HBS containing 2 $\mathrm{mM} \mathrm{Ca}{ }^{2+}$ and $1 \mathrm{mM} \mathrm{Ba}^{2+}$. Calibration bar: $50 \mathrm{mV}, 10 \mathrm{msec}(B) ; 50 \mathrm{mV}, 40$ $\operatorname{msec}(C)$. of nifedipine are sufficient to explain its failure to inhibit the electrically evoked release of SP.

\section{Materials and Methods}

Preparation of DRG cell cultures. Primary cultures of embryonic chick DRG cells were prepared as previously described (Dichter and Fischbach, 1977; Mudge et al., 1979; Dunlap and Fischbach, 1981). DRGs from 11- or 12-d-old embryos were incubated for $45 \mathrm{~min}$ in $\mathrm{Ca}^{2+}$ and $\mathrm{Mg}^{2+}$-free Puck's solution, resuspended in Eagle's Minimal Essential Medium (MEM, supplemented with $7 \mathrm{~S}$ nerve growth factor, $5 \%$ chick embryo extract, $10 \%$ horse serum, $1 \mathrm{~mm}$ glutamine, $50 \mathrm{U} / \mathrm{ml}$ penicillin, and $50 \mu \mathrm{g} / \mathrm{ml}$ streptomycin), and mechanically dissociated by trituration to give a single-cell suspension. The DRG cells were gamma-irradiated (5000 rads) and plated on $60 \mathrm{~mm}$ collagen-coated tissue culture dishes at a density of $150,000-200,000$ neurons/dish. This density is $2-2.5$ times that used in previous studies examining the electrophysiological properties of DRG cells (Dunlap and Fischbach, 1978, 1981). Culture medium was changed every $2-3 \mathrm{~d}$ beginning on day 3 . The peak phase of non-neuronal cell death was observed on days 3-5.

The plating density was a critical factor in these experiments. Lower plating densities resulted in poor cell adhesion and limited neurite outgrowth. Large numbers of non-neuronal cells were observed with higher plating densities. In both cases the cellular content of SP was reduced to less than $1 \mathrm{ng} /$ culture, whereas a cellular content of $10-15 \mathrm{ng} /$ culture was observed by day 16 in those cultures that we judged to be of optimal density. Highest levels of SP were observed in cultures exhibiting dense patterns of neurites, clear cell bodies with prominent nucleoli, and few non-neuronal cells. In those cultures the cells remained firmly attached to the collagen substrate even with repeated exchanges of the bathing solution.

Stimulation protocol for substance $P$ release experiments. DRG cell cultures were stimulated under sterile conditions at room temperature using bipolar platinum steel electrodes. This allowed repeated use of the same cultures for experiments on as many as 10 different days. As illustrated in Figure $1 A$, 2 electrodes were positioned opposite each other on the outer circumference of a plastic insert that fit snugly against the inner circumference of the culture dish. Each electrode occupied onethird of the circumference of the dish, and a roof over the stimulation chamber protected against drying of the chamber contents. Stimuli (square-wave DC pulses, $3 \mathrm{msec}$ duration, $110 \mathrm{~V}$ ) were delivered at 1 $\mathrm{Hz}$, and the stimulus polarity was reversed every $30 \mathrm{sec}$. Microelectrode recordings demonstrated that field stimulation generated action potentials of normal configuration in all cells tested (Fig. 1, B, C).

Composition of solutions. All solutions used in the release experiments consisted of saline buffered with $25 \mathrm{~mm}$ HEPES, pH 7.4. The HEPESbuffered saline (HBS) contained (in mM): $132 \mathrm{NaCl}, 2.5 \mathrm{KCl}, 2.0 \mathrm{CaCl}_{2}$, $0.8 \mathrm{MgCl}_{2}$, and $0.04 \% \mathrm{BSA}$. For solutions containing $1 \mathrm{mM} \mathrm{Ba}{ }^{2+}$ or 5 mM $\mathrm{Co}^{2+}$, an appropriate volume of concentrated $\mathrm{BaCl}_{2}$ or $\mathrm{CoCl}_{2}$ stock solution was added directly to the HBS. Nifedipine was obtained from Sigma, Bay K 8644 from Miles Laboratories, and $\omega-\mathrm{CgTx}$ from Penninsula Laboratories. Nifedipine and Bay K 8644 were prepared as concentrated ( $5 \mathrm{mM})$ stock solutions in absolute ethanol. Stock solutions were diluted in HBS to give $5 \mu \mathrm{M}$ test solutions (final concentration of ethanol, $0.10 \%$ ). In all experiments examining modulation of release by dihydropyridines, control solutions (i.e., no drugs added) contained $0.10 \%$ ethanol.

Radioimmunoassay for released substance $P$. Field stimulation-in- 
duced release of SP was measured by direct radioimmunoassay (RIA) of the solution bathing the cells. The RIA employed an antibody specific for authentic SP (l-1 l) and its sulfoxide derivative, with less than $0.01 \%$ cross-reactivity to the related tachykinins physalaemin and substance K (Kream et al., 1985). Tracer was synthesized by radioiodination of the Bolton-Hunter conjugate of SP. The specific activity of reversephase HPLC-purified tracer was approximately $2000 \mathrm{Ci} / \mathrm{mmol}$.

Prior to electrical field stimulation, each culture was bathed in 1.7 $\mathrm{ml}$ of the solution to be tested. Following field stimulation, a $1.64 \mathrm{ml}$ aliquot of the bathing solution was removed for RIA. To each $1.64 \mathrm{ml}$ test sample was added $60 \mu \mathrm{l}$ of RIA buffer, containing (in gm/liter): 44 $\mathrm{NaCl}, 10 \mathrm{BSA}, 20$ peptone, 0.2 cytochrome C, 3.7 disodium EDTA, 0.1 sodium azide, 60 HEPES, 0.01 aprotinin, 0.25 leupeptin, 25 pepstatin- $\mathrm{A}$, and 0.1 phenylmethylsulfonyl fluoride, $\mathrm{pH} 8.0$. Aliquots $(0.4$ $\mathrm{ml}$ ) of this HBS/RIA buffer solution were assayed in quadruplicate. To each aliquot was added $20 \mu \mathrm{l}$ of SP antibody such that the final antibody dilution factor was $150,000-250,000$-fold $(33-45 \%$ of the immunoreactive tracer was bound in this range of dilutions). Next, $20 \mu 1$ of ${ }^{125}$ I$\mathrm{SP}$ tracer was added $16 \mathrm{hr}$ following addition of the antibody. The assay was equilibrated for $24 \mathrm{hr}$, and bound tracer was separated from free tracer by precipitation and centrifugation of the antibody-tracer complex in $2 \mathrm{ml} 100 \%$ ethanol.

The sensitivity of the RIA was adjusted by varying the concentration of SP antibody. In most experiments, the $\mathrm{IC}_{50}$ value for displacement of immunoreactive tracer by nonradioactive SP was $125 \mathrm{pg} \mathrm{SP} /$ assay and the lower limit of detection was $16 \mathrm{pg} \mathrm{SP/assay.} \mathrm{Sensitivity} \mathrm{as} \mathrm{low}$ as $2 \mathrm{pg} \mathrm{SP/assay} \mathrm{was} \mathrm{obtained} \mathrm{with} \mathrm{more} \mathrm{dilute} \mathrm{antibody,} \mathrm{but} \mathrm{this} \mathrm{level}$ of detection was not required in most experiments. Standard curves were generated by assaying serial dilutions of synthetic SP standard (Sigma) that was diluted in the same HBS test solution as was used for the release experiment. Standard curves were linearized by logit-log transformation of these data. None of the drugs tested interfered with binding of the tracer to the antibody. The intra-assay coefficient of variation was less than $10 \%$.

Authentication of substance $P$ by HPLC. Authentication of SP extracted from DRG cell cultures was performed by reverse-phase HPLC as previously described (Kream et al., 1985). SP was extracted in $2 \mathrm{ml}$ of $6 \mathrm{~N}$ guanidine $\mathrm{HCl}$ and the extract subjected to an initial purification (step 1) by reverse-phase chromatography on Baker 10 SPE octadecyl C18 columns. SP was eluted in $2 \mathrm{ml}$ of $50 \% \mathrm{CH}_{3} \mathrm{CN}$ containing $0.1 \%$ $\mathrm{CF}_{3} \mathrm{COOH}$. Aliquots $(50 \mu \mathrm{l})$ were lyophilized, resuspended in RIA buffer, and assayed by RIA to determine the total cellular content of SP per culture.

HPLC was performed using a $3.9 \times 150 \mathrm{~mm}$ Waters C18 Nova-Pak column. The eluate from step 1 was diluted 10 -fold with distilled water, and $1 \mathrm{ml}$ aliquots of this solution were serially loaded onto the column. Elution was initially achieved under isocratic conditions $(8 \mathrm{~min})$, with a mobile phase of $15 \%(\mathrm{wt} / \mathrm{vol}) \mathrm{CH}_{3} \mathrm{CN}$ in $0.1 \% \mathrm{CF}_{3} \mathrm{COOH}$, followed by a linear $15-45 \%$ gradient of $\mathrm{CH}_{3} \mathrm{CN}$ in $0.1 \% \mathrm{CF}_{3} \mathrm{COOH}$ (30 min). The flow rate was $1 \mathrm{ml} / \mathrm{min}$, and $0.5 \mathrm{ml}$ fractions were collected. Aliquots $(50 \mu \mathrm{l})$ of each fraction were lyophilized, resuspended in buffer, and assayed for SP by RIA. Recovery of SP typically was $85-90 \%$.

Intracellular recordings from $D R G$ cell bodies. Intracellular microelectrode and voltage-clamp recordings of DRG cell action potentials and calcium currents were obtained as previously described (Dichter and Fischbach, 1977; Rane and Dunlap, 1986). In both recording configurations, the extracellular solution was the same as that used in the release experiments (the divalent cation concentrations were $2 \mathrm{mM} \mathrm{Ca}^{2+}$ and $1 \mathrm{mM} \mathrm{Ba}^{2+}$ ), except that $0.3 \mu \mathrm{M}$ tetrodotoxin was added to the solution when recording calcium currents. For whole-cell patch-clamp rcordings of calcium currents, the pipette solution contained (in mM): $150 \mathrm{CsCl}, 5$ bis $\left(o\right.$-aminophenoxy)ethane- $N, N, N^{\prime}, N$-tetraacetic acid (BAPTA), $5 \mathrm{MgATP}$, and 10 HEPES (pH 7.3). All drugs were applied by pressure-ejection from a blunt-tipped micropipette.

\section{Results}

\section{Authentication of substance $P$ immunoreactivity}

Release experiments were performed using 9-16-d-old DRG cell cultures. In preliminary experiments it was demonstrated that electrical field stimulation at $1 \mathrm{~Hz}$ for $30 \mathrm{sec}$ resulted in the appearance of detectable levels of SP immunoreactivity in the bathing solution. SP synthesized by DRG cells was judged to be authentic SP on the basis of chromatographic and im-

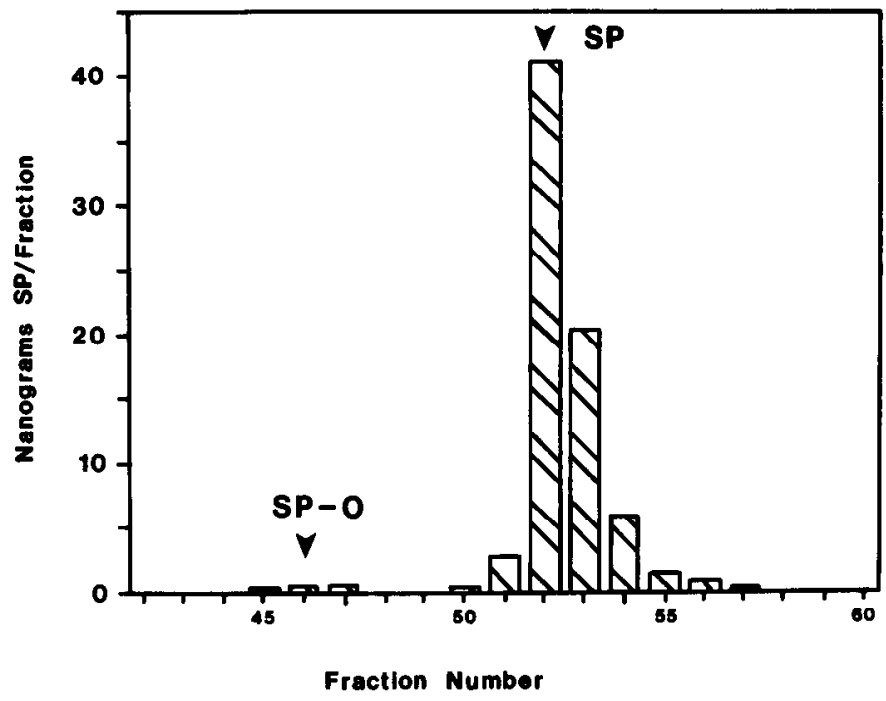

Figure 2. Authentication of SP immunoreactivity by HPLC. The cellular content of SP from 6 cultures was extracted in $6 \mathrm{~N}$ guanidine $\mathrm{HCl}$ and fractionated by HPLC as described in Materials and Methods. Fractions $(0.5 \mathrm{ml})$ were collected and $20 \mu \mathrm{l}$ aliquots assayed for SP by RIA. The elution profile of DRG cell SP is indicated by the cross-hatched columns. The arrowheads indicate the position determined for the major immunoreactive fractions of synthetic SP and the sulfoxide derivative of SP $(S P-O)$.

munoreactive properties. DRG cell extracts were fractionated by reverse-phase HPLC, and the elution profile of cellular SP was monitored by RIA. As illustrated in Figure 2, the retention time for cellular SP matched that of synthetic SP standard. In addition, a smaller peak corresponding to the sulfoxide derivative (SP-O, to which the antibody cross-reacts; Kream et al., 1985) of SP was also noted.

As expected, SP extracted, or released, from DRG cell cultures displayed a dose-dependent displacement of the binding of ${ }^{125} \mathrm{I}$ SP to the SP antibody. As illustrated in Figure 3, a standard curve was generated by assaying serial dilutions of synthetic SP. When serial dilutions of cellular extract (Fig. 3, square symbols) or released SP (circles) were assayed, the displacement curves generated displayed slopes identical to the standard curve (triangles). For these reasons, the immunoreactivity recognized by our antibody will henceforth be referred to as SP.

\section{Characterization of the effects of divalent cations on field stimulation-induced release of substance $P$}

We characterized the effects of electrical field stimulation on the SP release process. As illustrated in Figure 4, when cultures were bathed in HBS containing $3 \mathrm{mM} \mathrm{Ca}^{2+}$, stimulation $(5 \mathrm{~min}$ at 1 $\mathrm{Hz}$ ) increased SP levels in the bathing solution 4.5-fold over baseline values (unstimulated: $68 \pm 16 \mathrm{pg} /$ culture; stimulated: $305 \pm 26 \mathrm{pg} /$ culture; mean $\pm \mathrm{SEM} ; n=3$ ). The amount of SP released was $2.3 \%$ of the total cellular content of SP per culture (total cellular content was calculated as the sum of the amount released plus the amount remaining in the cells).

The release of SP was calcium-dependent: it was blocked by HBS containing $0.1 \mathrm{mM} \mathrm{Ca}^{2+}$ and $5.0 \mathrm{mM} \mathrm{Co}^{2+}$ (Fig. 4). In contrast, a marked facilitation of release was observed when the HBS contained $1 \mathrm{mM} \mathrm{Ba}^{2+}$ and $2 \mathrm{mM} \mathrm{Ca}^{2+}$. In fact, $\mathrm{Ba}^{2+}$ more than doubled the amount of SP released (Fig. 4). Note that in the presence of $\mathrm{Ca}^{2+}, 1 \mathrm{mM} \mathrm{Ba}^{2+}$ was not a secretogogue: baseline levels of SP were not elevated relative to control. Intracellular 
Figure 3. Parallel displacement curves generated for synthetic, cellular, and released SP. Displacement curves were linearized by logit-log transformation of the binding data. A standard curve was generated by assaying serial dilutions of synthetic SP (triangles, upper abscissa). Cellular and released SP were subjected to an initial purification on Baker 10 SPE $\mathrm{C} 18$ columns, as described in Materials and Methods. SP

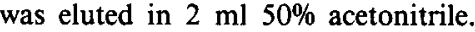
Serial dilutions of the eluates were assayed for SP by RIA, and displacement curves generated for cellular (squares) and released (circles) SP. The lower abscissa indicates the volume (in $\mu$ l) of the original $2 \mathrm{ml}$ eluate that was assayed by RIA.
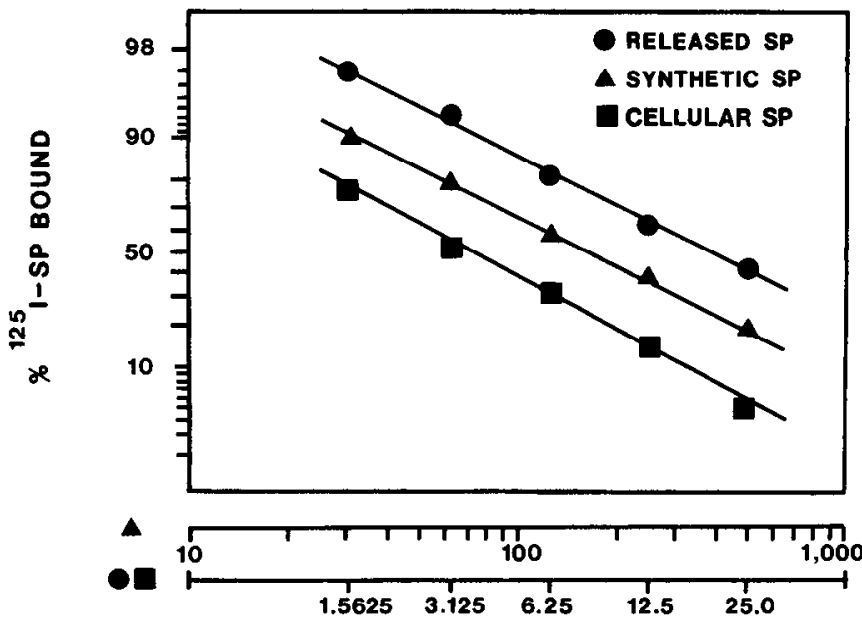

PG/ASSAY UI/ASSAY recordings demonstrated that the action of $\mathrm{Ba}^{2+}$ can be explained by its effect on the duration of DRG cell action potentials. As illustrated in the inset of Figure 4, these action potentials exhibit a plateau phase that is reduced in duration by $\mathrm{Co}^{2+}$ and increased in duration by $\mathrm{Ba}^{2+}$ (Dichter and Fischbach, 1977). Since the duration of the plateau phase is directly related to the amount of $\mathrm{Ca}^{2+}$ that enters with each action potential, it is likely that $\mathrm{Ba}^{2+}$ facilitates the release of SP by increasing spike duration.

\section{Determination of the stimulus-response relationship}

Figure 5 illustrates the stimulus-response relationship for field stimulation-induced release of SP over a range of 60-600 stimuli delivered at a frequency of $1 \mathrm{~Hz}$. In these experiments the HBS contained $1 \mathrm{mM} \mathrm{Ba}^{2+}$ and $2 \mathrm{mM} \mathrm{Ca}^{2+}$ in order to maximize the amount of SP released. Baseline and evoked levels of SP were calculated as a percentage of the total cellular content of SP per culture. Following field stimulation for $5 \mathrm{~min}$, the amount of $\mathrm{SP}$ in the bathing solution was increased by ca. 15-fold over baseline.

\section{Dihydropyridines modulate DRG cell calcium currents and neuropeptide secretion}

Previous single-channel recording studies of chick DRG cells demonstrated that Bay K 8644, a DHP calcium-channel agonist, facilitates current flow through a specific subtype of calcium channel. These high-threshold, slowly inactivating calcium channels were designated as L-type by Nowycky et al. (1985a, b). In addition, Rane et al. (1987) recently reported that current flow through these same channels is inhibited by nifedipine, a DHP calcium-channel antagonist. We examined the effects of DHPs on DRG cell action potentials and calcium currents in order to determine whether their effects on calcium influx might be correlated with their effects on the release of SP.

Figure 6 illustrates the effects of DHPs on DRG cell action potentials and L-type calcium currents recorded from cells bathed in the same extracellular solution as was used in the release experiments. Intracellular microelectrode recordings demonstrated that Bay K $8644(5 \mu \mathrm{M})$ increased the duration of the
Figure 4. Effects of divalent cations on the electrically evoked release of SP. Nine cultures from the same plating were divided into 3 sets of 3 , and each set was bathed in HBS containing either $3 \mathrm{mM} \mathrm{Ca}^{2+}, 1 \mathrm{mM} \mathrm{Ba}^{2+}$ plus $2 \mathrm{mM} \mathrm{Ca}^{2+}$, or $0.1 \mathrm{mM} \mathrm{Ca}^{2+}$ plus $5 \mathrm{mM} \mathrm{Co}^{2+}$, as indicated. Baseline (shaded columns) and evoked (unshaded columns) levels of SP were determined after 5 min exposure to each solution. Stimuli were delivered at $1 \mathrm{~Hz}$. Each column indicates the mean \pm SEM for 3 cultures. The average cellular content of SP was $13,250 \pm 500 \mathrm{pg} /$ culture $(n=9)$. Inset, DRG cell action potentials recorded in each solution. Calibration bars, 10 $\mathrm{msec}, 20 \mathrm{mV}$. Note that $\mathrm{Ba}^{2+}$ increased the action potential duration and facilitated SP release, whereas $\mathrm{Co}^{2+} \mathrm{de}-$ creased the action potential duration and inhibited SP release.

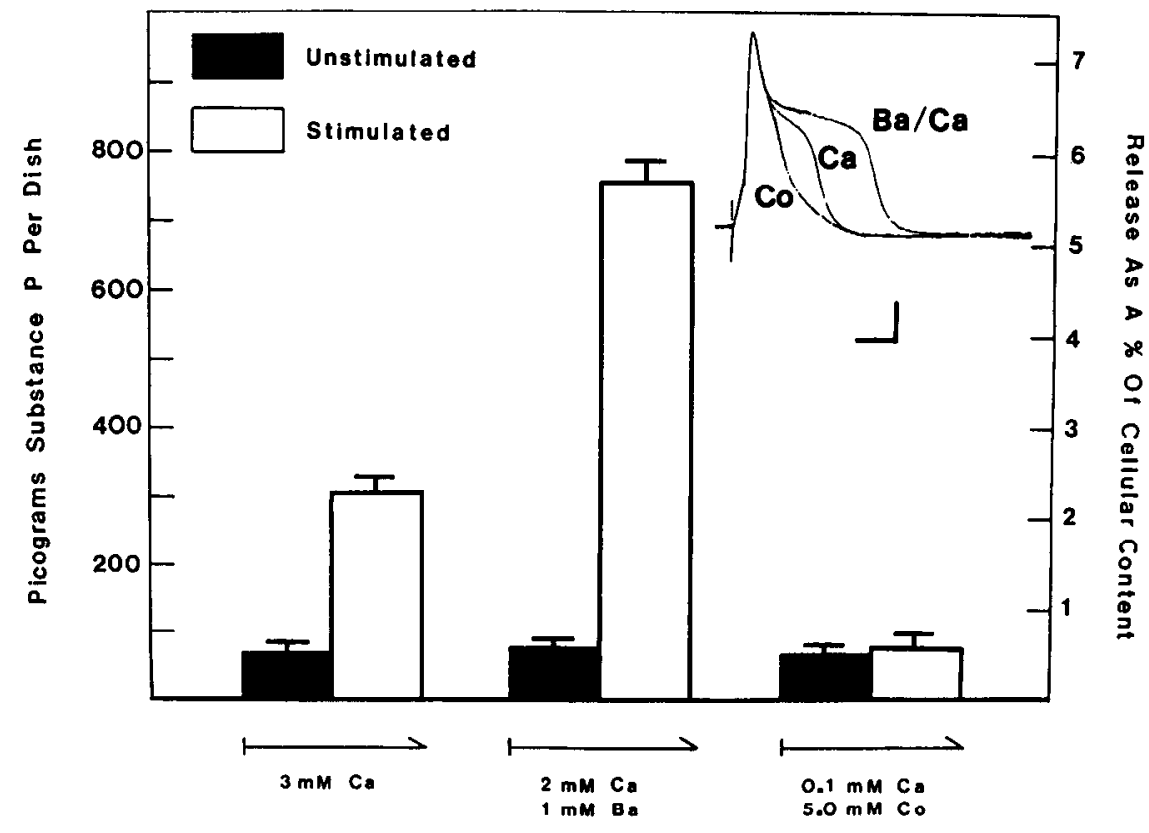




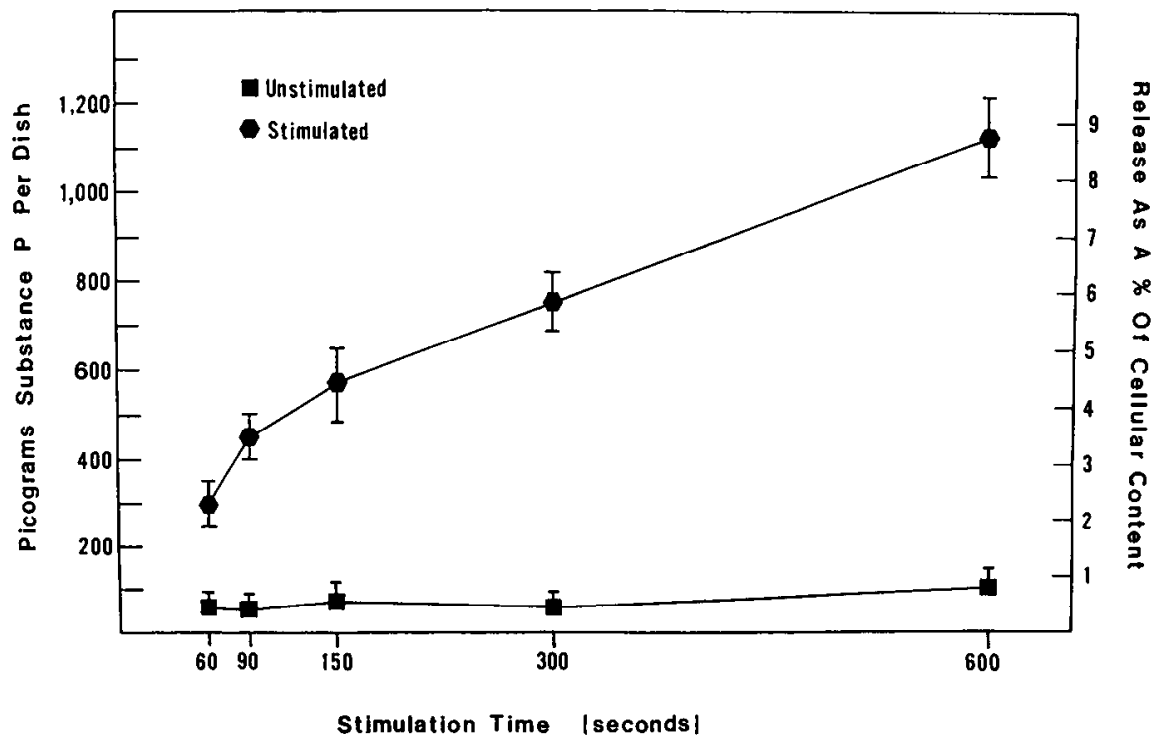

Figure 5. Stimulus-response relationship for electrically evoked release of SP. Fifteen DRG cell cultures from the same plating were divided into 5 sets of 3 , and each set was stimulated for either $60,90,150,300$, or $600 \mathrm{sec}$ at $1 \mathrm{~Hz}$. The $\mathrm{HBS}$ contained $1 \mathrm{~mm} \mathrm{Ba}{ }^{2+}$ and $2 \mathrm{mM} \mathrm{Ca}^{2+}$. Each point indicates the mean \pm SEM value for 3 cultures. The average cellular content of SP was $12,800 \pm 600 \mathrm{pg} /$ culture $(n=15)$. action potential in 14 of 18 cells tested, and increased the amplitude of the L-type calcium current (Fig. $6, A, B$ ). In contrast, in 20 of 20 cells tested, nifedipine $(5 \mu \mathrm{M})$ failed to alter the duration of the action potential (Fig. 6C), but decreased the amplitude of the L-type calcium current in 9 of 13 cells (average decrease of $38 \pm 5 \%$; mean \pm SEM) when the current was evoked from a relatively depolarized holding potential ( -30 $\mathrm{mV}$ ) that had been maintained for $5 \mathrm{sec}$ or more, as illustrated in Figure $6 E$. In contrast, when the L-type current was evoked from a holding potential that approximated the normal resting potential of DRG neurons $(-70 \mathrm{mV})$, nifedipine was relatively ineffective (Fig. 6D). These findings are consistent with the previously reported voltage and time-dependent actions of DHPs on L-type currents (Sanguinetti and Kass, 1984; Sanguinetti et al., 1986; Rane et al., 1987).

Next, we examined the effects of Bay K 8644 and nifedipine on SP release in order to determine whether the release process is triggered by calcium influx through L-type calcium channels. Neuropeptide secretion was induced by either field stimulation or depolarization with $\mathrm{HBS}$ containing $60 \mathrm{mM} \mathrm{KCl}$. The amount of SP released was calculated as a percentage of the total cellular content of SP per culture prior to stimulation. As summarized in Table 1A, under conditions in which the HBS contained 2 $\mathrm{mM} \mathrm{CaCl}$ and $1 \mathrm{mM} \mathrm{BaCl}_{2}$, treatment with Bay K $8644(5 \mu \mathrm{M})$ increased field stimulation-induced release of SP by $45 \%$ relative to control. In contrast, nifedipine ( $5 \mu \mathrm{M}$, a concentration that is saturating for inhibition of L-type calcium currents in DRG neurons; Rane et al., 1987) did not significantly affect the release of SP, although an inhibitory trend was noted (Table 1A).

The failure of nifedipine to inhibit the electrically evoked release of SP can be explained by the fact that this DHP inhibits calcium-channel function in a voltage and time-dependent manner (cf. Fig. 6, $D, E$ ). That is, in previous studies of L-type calcium currents, the inhibitory action of nifedipine was accentuated by prior depolarization of the resting membrane potential (Sanguinetti and Kass, 1984; Rane et al., 1987). We tested for such a voltage and time-dependent action of nifedipine by examining its effects on the release of SP induced by prolonged depolarization of cultures with $\mathrm{KCl}$.

When the release of SP was induced by $60 \mathrm{mM} \mathrm{KCl}$, the actions of the DHPs became much more pronounced. In these exper- iments, baseline values of SP were determined by exposing cultures for $5 \mathrm{~min}$ to HBS containing (in $\mathrm{mm}$ ): $132 \mathrm{NaCl}, 2.5 \mathrm{KCl}$, $2 \mathrm{CaCl}_{2}$, and $1 \mathrm{BaCl}_{2}$. For DHP-treated cultures, baseline values were determined in the presence of nifedipine or Bay K 8644. Next, cultures were depolarized for $5 \mathrm{~min}$ by $\mathrm{HBS}$ containing reduced $\mathrm{NaCl}(74 \mathrm{~mm})$ and elevated $\mathrm{KCl}(60 \mathrm{~mm})$. Intracellular recordings demonstrated that this concentration of $\mathrm{KCl}$ depolarized the resting membrane potential to $-26 \pm 1 \mathrm{mV}(n=5$ neurons), thereby inducing the calcium-dependent release of SP. As summarized in Table 1B, Bay K $8644(5 \mu \mathrm{M})$ more than doubled the amount of SP released relative to control, whereas

Table 1. Effects of dihydropyridines on the release of substance $P$

Change from

A. Field stimulation-induced release of SP Control

$\begin{array}{llll}(n=5) & 0.4 \pm 0.1 & 9.6+0.6 & - \\ \begin{array}{c}\text { Nifedipine } \\ (n=5)\end{array} & 0.6 \pm 0.1 & 8.2 \pm 0.9 \text { (n.s.) } & 17 \% \text { decrease } \\ \begin{array}{c}\text { Bay K } 8644 \\ (n=5)\end{array} & 0.4 \pm 0.2 & 13.7 \pm 0.8^{*} & 45 \% \text { increase }\end{array}$

B. $60 \mathrm{~mm} \mathrm{KCl-induced} \mathrm{release} \mathrm{of} \mathrm{SP}$

Control

$\begin{array}{cccc}(n=5) & 0.5 \pm 0.1 & 3.8 \pm 0.5 & - \\ \begin{array}{c}\text { Nifedipine } \\ (n-5)\end{array} & 0.4 \pm 0.2 & 1.8 \pm 0.1^{* *} & 58 \% \text { dccrcasc } \\ \begin{array}{c}\text { Bay K 8644 } \\ (n=5)\end{array} & 0.6 \pm 0.2 & 7.7 \pm 0.5^{* *} & 115 \% \text { increase }\end{array}$

Results of 2 representative experiments using 30 cultures from 2 different platings. Each experiment assessed the effects of nifedipine and Bay K 8644 on the electrically and $\mathrm{KCl}$-induced release of SP from cultures of the same plating. Values from both experiments were then averaged. Baseline and evoked levels of SP are expressed as a percentage of the total cellular content of SP per culture prior to stimulation. Values are the mean \pm SEM for the indicated number of cultures. A, Cultures were electrically stimulated for $5 \mathrm{~min}$ at $1 \mathrm{~Hz}$, whereas B, cultures were depolarized for $5 \mathrm{~min}$ by $\mathrm{HBS}$ containing $60 \mathrm{~mm} \mathrm{KCl}$. The percentage change relative to control was calculated after substracting baseline values from evoked values. Data were analyzed by Student's $t$ test: * Value is significantly different from control: $p \leq 0.005 ;{ }^{* *} p \leq 0.001 ;$ n.s., value is not significantly different from control: $p>$ 0.1 . The average cellular content was $14,200 \pm 250 \mathrm{pg}$ SP/culture $(n=30)$. 
A

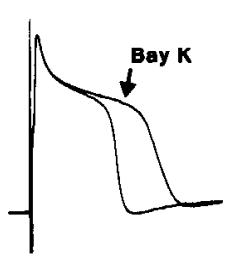

8

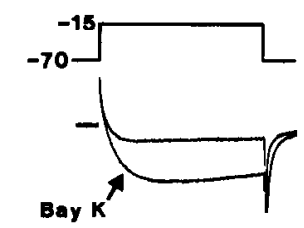

C
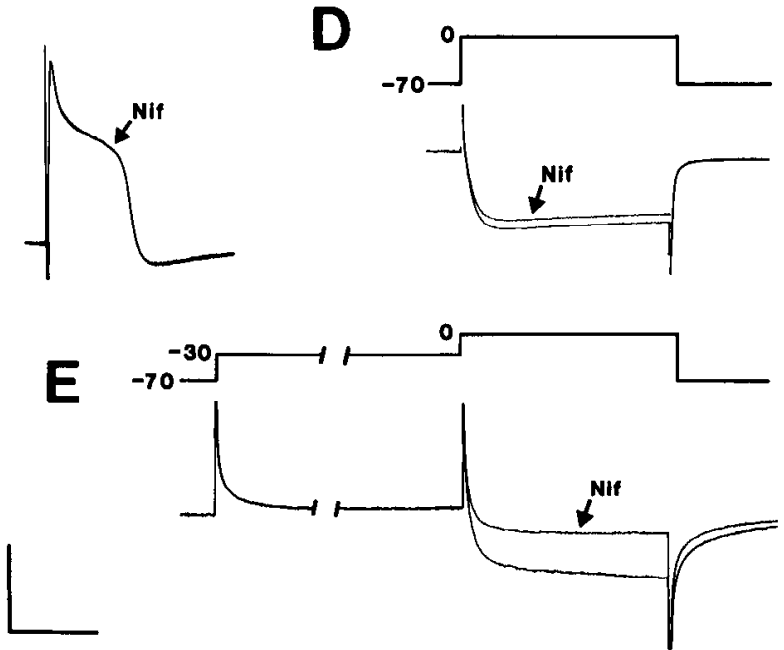

Figure 6. Effects of Bay K $8644(5 \mu \mathrm{M})$ and nifedipine $(5 \mu \mathrm{M})$ on DRG cell action potentials and L-type calcium currents. Bay K 8644 increased the action potential duration $(A)$, whereas nifedipine was without effect (C). As shown in $B$, Bay $\mathrm{K} 8644$ also increased the amplitude of the L-type calcium current (lower trace) when cells were held at $-70 \mathrm{mV}$ and depolarized to $-15 \mathrm{mV}$ for $40 \mathrm{msec}$ (upper trace). D, E, Voltage and time-dependent inhibitory actions of nifedipine on L-type calcium currents. When cells were held at $-70 \mathrm{mV}$ and depolarized to $0 \mathrm{mV}$ for $60 \mathrm{msec}$, nifedipine was a relatively weak antagonist $(D)$. In contrast, when cells were held at $-70 \mathrm{mV}$, stepped to $-30 \mathrm{mV}$ for $5 \mathrm{sec}$, and then depolarized to $0 \mathrm{mV}$ for $60 \mathrm{msec}$, the inhibitory action of nifedipine was revealed $(E)$. In $A-E$ the bathing solution was HBS containing 2 $\mathrm{mm} \mathrm{Ca}{ }^{2+}$ and $1 \mathrm{mM} \mathrm{Ba}{ }^{2+}$. All examples are representative recordings obtained from different cells. Calibration bar: $50 \mathrm{mV}, 40 \mathrm{msec}(A, C)$; $4 \mathrm{nA}, 25 \mathrm{msec}(B, D) ; 0.8 \mathrm{nA}, 25 \mathrm{msec}(E)$.

nifedipine $(5 \mu \mathrm{M})$ reduced the amount of SP released by $58 \%$. At these concentrations, neither Bay K 8644 nor nifedipine significantly affected baseline levels of SP.

\section{Conus toxin blocks DRG cell calcium currents and substance $P$ release}

It was recently reported that the molluscan neurotoxin $\omega-\mathrm{CgTx}$, isolated from Conus geographus by Olivera et al. (1984), inhibits calcium influx associated with DRG action potentials (Kerr and Yoshikami, 1984) and blocks L- and $\mathrm{N}$-type calcium currents in DRG cell bodies (McCleskey et al., 1986; Feldman et al., 1987). To further substantiate a role for L-type calcium channels in neuropeptide secretion, we examined the effects of $\omega-\mathrm{CgTx}$ on the electrically evoked release of SP. As illustrated in Figure $7, A-C, \omega-\mathrm{CgTx}(1 \mu \mathrm{M})$ decreased the duration of DRG cell action potentials, irreversibly blocked the L-type calcium current, and inhibited the electrically evoked release of SP.

\section{Discussion}

\section{Calcium-dependent release of substance $P$}

The findings of the present study confirm previous reports that embryonic chick DRG neurons synthesize and secrete authentic SP when grown in primary dissociated cell culturc (Mudge, 1979,
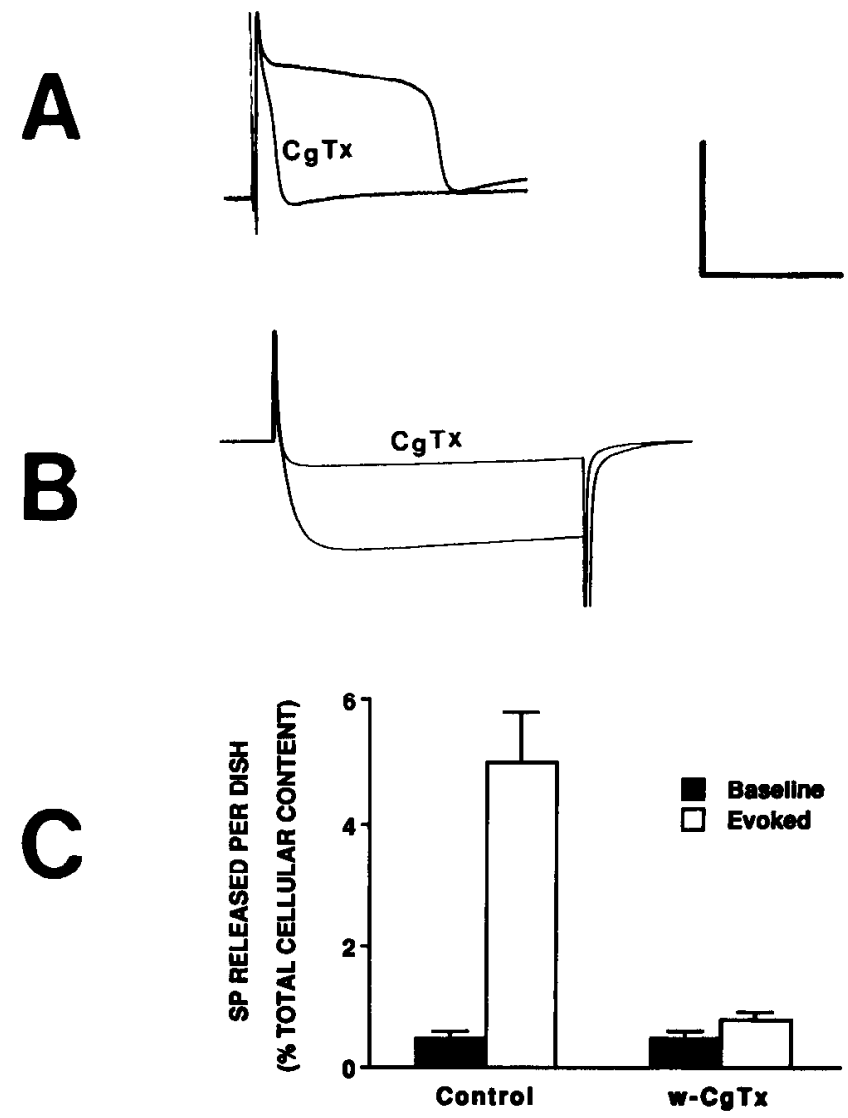

Figure 7. Analysis of the effects of $\omega$-CgTx. Application of $\omega-\mathrm{CgTx}(1$ $\mu \mathrm{M})$ decreased the duration of the DRG cell action potential $(A)$, decreased the amplitude of the L-type calcium current $(B)$, and blocked the electrically evoked release of SP $(C)$. Calcium currents were evoked from a holding potential of $-70 \mathrm{mV}$ in response to step depolarizations to $0 \mathrm{mV}$ for $60 \mathrm{msec}$. In $A-C$ the bathing solution was HDS containing $2 \mathrm{mM} \mathrm{Ca}^{2+}$ and $1 \mathrm{mM} \mathrm{Ba}^{2+}$. For analysis of the effects of $\omega$-CgTx on SP release, 6 cultures from the same plating were divided into 2 sets of 3 . Each set was stimulated at $1 \mathrm{~Hz}$ for $3 \mathrm{~min}$, and the amount of SP released was calculated as a percentage of the total cellular content of SP per culture prior to stimulation. Calibration bar: $80 \mathrm{mV}, 40 \mathrm{msec}(A) ; 0.8$ nA, $25 \mathrm{msec}(B)$.

1981; Mudge et al., 1979). These earlier studies examined the mechanism by which depolarizing concentrations of $\mathrm{KCl}$ induce neuropeptide secretion. We have extended these original observations by characterizing the electrically evoked release of $\mathrm{SP}$ in terms of its calcium-dependence, stimulus-response relationship, and its modulation by $\omega-\mathrm{CgTx}$ and DHPs.

Three observations indicate that the electrically evoked release of SP does not result from nonspecific electropermeabilization of DRG cell membranes. First, intracellular recordings demonstrated that DRG neurons fire action potentials of normal configuration in response to electrical field stimulation. Secondly, the electrically evoked release of SP was fully repeatable, and, following stimulation, baseline levels of released SP returned to prestimulus levels, indicating that field stimulation does not damage the cells. Third, release was blocked by solutions containing either $5 \mathrm{mM} \mathrm{Co}{ }^{2+}$ or $1 \mu \mathrm{M} \omega-\mathrm{CgTx}$. This is as expected for a process of calcium-dependent exocytosis, since little or no depolarization-induced calcium current is recorded from the soma membrane of DRG neurons bathed in such solutions (Dunlap and Fischbach, 1981; Fig. 7). Therefore, the 
electrically evoked release of SP appears to be triggered by calcium influx through voltage-dependent calcium channels.

\section{$A$ role for L-type calcium channels in neuropeptide secretion}

We have also demonstrated that the release of SP is facilitated by the DHP calcium-channel agonist Bay K 8644 , and is inhibited by the DHP calcium-channel antagonist nifedipine. Significantly, it is now known that Bay K 8644 and nifedipine modulate slowly inactivating L-type calcium currents recorded from the soma membrane of DRG neurons (Nowycky et al., $1985 \mathrm{a}, \mathrm{b}$; Rane et al., 1987). In contrast, fast-inactivating (Nand T-type) calcium currents do not appear to be affected by either drug (Nowycky et al., 1985a, b; Rane et al., 1987). On the basis of these findings, we propose that DHPs modulate the release of SP by regulating calcium influx through L-type calcium channels located at release sites on primary afferent neurons.

It remains to be determined exactly where these release sites are located. For example, it might be argued that the release of SP is triggered by calcium influx through L-type calcium channels located in sensory nerve terminals. Alternatively, an action of Bay K 8644 or nifedipine on L-type calcium channels located in the somatic membrane of DRG neurons might explain the DHP sensitivity of the SP release mechanism. It is therefore important to recognize the limitations of release experiments conducted in dissociated cell culture where the sites of neuropeptide secretion remain undefined.

\section{Voltage- and time-dependent actions of nifedipine}

In the present study it was found that nifedipine inhibited the release of SP only under conditions of $\mathrm{KCl}$-induced depolarization. No significant inhibitory action of the antagonist was observed when release was induced by electrical field stimulation. Moreover, nifedipine failed to inhibit calcium influx associated with DRG cell action potentials. These findings are explicable in terms of the voltage and time-dependent actions of DHPs on L-type calcium currents. Specifically, it was previously reported, and confirmed in the present study, that nifedipine inhibits L-type calcium currents most effectively when the membrane potential is held at depolarized levels $(\leq-30$ $\mathrm{mV}$ ) for $5 \mathrm{sec}$ or more (Sanguinetti and Kass, 1984; Rane et al., 1987). Clearly, such conditions are not achieved during electrical field stimulation, where SP release is triggered by action potentials of relatively short duration $(10-50 \mathrm{msec})$ evoked from resting membrane potentials of -60 to $-70 \mathrm{mV}$.

In contrast, when cultures were depolarized by $60 \mathrm{~mm} \mathrm{KCl}$, $5 \mu \mathrm{M}$ nifedipine inhibited the release of SP by $58 \%$. Similar inhibitory actions of DHP calcium-channel antagonists were reported in previous studies examining $\mathrm{KCl}$-induced calcium uptake into, or transmitter release from, rat DRG cells (Perney et al., 1986), cerebellar and retinal neurons (Takahashi and Ogura, 1983; Carboni et al., 1985), neuronal cell lines (Freedman et al., 1984), PC 12 cells (Toll, 1982), pituitary cells (Enyeart et al., 1985; Chang et al., 1986), and rat brain synaptosomes (Turner and Goldin, 1985).

\section{Modulation of substance $P$ release by Bay $K 8644$}

The action of Bay K 8644 differed from that of nifedipine in that this calcium-channel agonist facilitated both the KCl-induced and electrically evoked release of SP. Furthermore, Bay K 8644 increased calcium influx associated with DRG cell action potentials. These findings are also explicable in terms of the voltage and time-dependent actions of DHPs. Modulation of L-type calcium currents by Bay K 8644 does not require prior depolarization of the membrane potential. In fact, the agonist action of Bay K 8644 is most easily observed when L-type calcium currents are evoked from membrane potentials $(-70$ $\mathrm{mV}$ ) close to the normal resting potential of DRG cells (see Fig. $6, A, B$; see also Nowycky et al., 1985a, b; Sanguinetti et al., 1986). Such conditions are achieved during electrical field stimulation of DRG cells.

\section{How these findings relate to previous studies examining the DHP sensitivity of neurosecretion}

The findings reported herein are noteworthy in that they emphasize the limited usefulness of DHPs as pharmacological probes for L-type calcium channels. In particular, we have demonstrated that nifedipine inhibits, but does not completely block, the L-type calcium current, and that this antagonist action is both voltage and time-dependent. An understanding of such limitations is essential in order to properly evaluate previous studies reporting the failure of DHP calcium-channel antagonists to inhibit $\mathrm{KCl}$-induced transmitter release from synaptosomal and brain slice preparations (reviewed by Miller, 1985). This failure to block secretion has been taken to indicate that in the central nervous system, calcium influx through L-type calcium channels does not normally trigger transmitter release (reviewed by Miller, 1987).

The findings of the present study suggest an alternative interpretation. We propose that the relatively slow antagonist action of DHPs (as reported here, and previously by Sanguinetti and Kass, 1984; Rane et al., 1987) severely limits their ability to inhibit transmitter release triggered by calcium influx during the initial phase (i.e., first $5 \mathrm{sec}$ ) of $\mathrm{KCl}$-induced depolarization. This model predicts that antagonist DHPs will be effective only when the time course of transmitter release overlaps with the onset of L-type calcium-channel blockade, as is apparently the case during $\mathrm{KCl}$-induced release of SP from DRG cell cultures.

In contast, in those systems in which calcium influx and transmitter release are very transient in nature, no effect of antagonist DHPs is to be expected. For cxample, it was previously reported that DHPs fail to inhibit $\mathrm{KCl}$-induced calcium uptake into rat brain synaptosomal preparations (Nachshen and Blaustein, 1979; Daniell et al., 1983; Reynolds et al., 1986; Suszkiw et al., 1986). However, it is also well documented that the rapid phase of $\mathrm{KCl}$-induced calcium uptake into, and transmitter release from, synaptosomes is primarily limited to the first $1-2 \mathrm{sec}$ of sustained depolarization (Drapeau and Blaustein, 1983; Floor, 1983; Turner and Goldin, 1985; Suszkiw et al., 1986). Our findings indicate that this time course of calcium influx may be too transient to allow effective blockade of the synaptosomal release mechanism by DHPs. In fact, such transient kinetics may result from rapid calcium-dependent inactivation of L-type calcium channels as intracellular levels of free calcium rise (Eckert and Chad, 1984). For these reasons, we wish to emphasize that in future studies examining the actions of DHPs, it will be necessary to obtain detailed information regarding the time course of calcium influx and transmitter release.

\section{What is the role of $N$ - and T-type calcium channels?}

An important question that remains to be answered is whether calcium influx through $\mathrm{N}$ - or T-type calcium channels also triggers the release of SP from DRG neurons. On the basis of previous studies examining $\mathrm{N}$ - and T-type calcium currents in 
the chick DRG soma membrane (Nowycky et al., 1985a), we would expect such a mechanism of release to exhibit DHP insensitivity. In fact, we found that $5 \mu \mathrm{M}$ nifedipine inhibited the $\mathrm{KCl}$-induced release of SP by only $58 \%$. Moreover, the electrically evoked release of SP was relatively insensitive to nifedipine. Although these obervations are most simply explained by the voltage and time-dependent actions of DHPs on L-type calcium channels (as summarized above), it remains possible that DHP-insensitive (N- or T-type) calcium channels also play a role in the secretion process.

For example, it might be argued that the electrically evoked (and therefore physiologically relevant) release of SP results from calcium influx through $\mathrm{N}$ - or T-type channels, whereas L-type channels mediate secretion induced by $\mathrm{KCl}$ (see Miller, 1987). Our observation that $\omega$-CgTx blocked the electrically evoked release of SP appcars to rulc out such a rolc for T-typc channcls, since current flow through this channel subtype was reported to be insensitive to the toxin (McCleskey et al., 1987). Therefore, the release of SP most likely results from $\mathrm{Ca}^{2+}$ influx through either N- or L-type channels, or possibly both. It must be emphasized, however, that the $\omega-\mathrm{CgTx}$ effects reported herein do not resolve the question of which channel subtype is most important to the secretory process. Micromolar concentrations of $\omega$-CgTx were previously reported to block both $\mathrm{N}$ - and L-type calcium currents (McCleskey et al., 1987). Therefore, this question will only be answered when more specific pharmacological probes for $\mathrm{N}$ - and L-type calcium channels are discovered.

\section{Transmitter modulation of DHP-sensitive calcium channels}

It was previously reported that norepinephrine (NE) and GABA inhibit DHP-sensitive, L-type calcium currents recorded from chick DRG cell bodies (Dunlap and Fischbach, 1981; Holz et al., 1986a; Rane et al., 1987). Since NE and GABA also inhibit the calcium-dependent release of SP from chick DRG cell cultures (Dunlap et al., 1986; Holz et al., 1986b), the transmitters may presynaptically inhibit neuropeptide secretion by regulating calcium influx through L-type calcium channels located at release sites on sensory nerve terminals (Dunlap et al., 1987). The findings of the present study support this concept. We have demonstrated that the depolarization-induced release of SP exhibits DHP sensitivity, as would be expected if calcium influx through L-type calcium channels triggers neuropeptide secretion. It may be concluded that in primary afferent neurons, the regulation of L-type calcium channels by neurotransmitters is likely to play an important role in processes governing the inhibition or facilitation of ncurosccretion.

\section{References}

Carboni, E., W. J. Wojcik, and E. Costa (1985) Dihydropyridines change the uptake of calcium induced by deplolarization into primary cultures of cerebellar granule cells. Neuropharmacology 24: 11231126.

Chang, M. M., and S. F. I eeman (1970) Isolation of a sialogogic peptide from bovine hypothalamic tissue and its characterization as substance P. J. Biol. Chem. 245: 4784-4790.

Chang, J. P., E. M. McCoy, J. Graeter, K. Tasaka, and K. Catt (1986) Participation of voltage-dependent calcium channels in the action of gonadotropin-releasing hormone. J. Biol. Chem. 261: 9105-9108.

Daniell, L. C., E. M. Barr, and S. W. Leslie (1983) Ca uptake into rat whole brain synaptosomes unaltered by dihydropyridine calcium antagonists. J. Neurochem. 41: 1455-1459.

Dichter, M. A., and G. D. Fischbach (1977) The action potential of chick dorsal root ganglion neurones maintained in cell culture. J. Physiol. (Lond.) 267: 281-298.

Drapeau, P., and M. P. Blaustein (1983) Initial release of dopamine from rat striatal synaptosomes: Correlation with calcium entry. $J$. Neurosci. 3: 703-713.

Dunlap, K., and G. D. Fischbach (1978) Neurotransmitters decrease the calcium component of sensory neurone action potentials. Nature 276: 837-839.

Dunlap, K., and G. D. Fischbach (1981) Neurotransmitters decrease the calcium conductance activated by depolarization of embryonic chick sensory neurons. J. Physiol. (Lond.) 317: 519-535.

Dunlap, K., R. M. Kream, and G. G. Holz IV (1986) Alpha-2 adrenergic and GABA-B receptors mediate transmitter inhibition of neuropeptide secretion from dorsal root ganglion cells. Soc. Neurosci. Abstr. 12: 1195.

Dunlap, K., S. G. Rane, and G. G. Holz IV (1987) Functional implications of calcium channel modulation in embryonic dorsal root ganglion neurons. In Ion Channel Modulation, A. D. Grinnell, D. L. Armstrong, and M. B. Jackson, eds., Plenum (in press).

Eckert, R., and J. E. Chad (1984) Inactivation of Ca channels. Prog. Biophys. Mol. Biol. 44: 215-267.

Enyeart, J. J., T. Aizawa, and P. M. Hinkle (1985) Dihydropyridine $\mathrm{Ca}$ antagonists: Potent inhibitors of secretion from normal and transformed pituitary cells. Am. J. Physiol. 248: C510-C519.

Feldman, D. H., B. M. Olivera, and D. Yoshikami (1987) Omega conus toxin: A peptide that blocks calcium channels. FEBS Lett. 214: 295-300.

Tloor, E. (1983) Substance P release from K-depolarized rat brain synaptosomes at one second resolution. Brain Res. 279: 321-324.

Freedman, S. B., G. Dawson, M. L. Villereal, and R. J. Miller (1984) Identification and characterization of voltage-sensitive calcium channels in neuronal clonal cell lines. J. Neurosci. 4: 1453-1467.

Gamse, R., A. Molnar, and F. Lembeck (1979) Substance P release from spinal cord slices by capsaicin. Life Sci. 25: 629-636.

Goetzl, E. J., T. Chernov, F. Renold, and D. G. Payan (1985) Neuropeptide regulation of the expression of immediate hypersensitivity. J. Immunol. 135: 802s-805s.

Henry, J. L. (1977) Substance $P$ and pain: A possible relation in afferent transmission. In Substance P, U.S. von Euler and B. Pernow, eds., pp. 231-239, Raven, New York.

Henry, J. L. (1982) Relation of substance P to pain transmission: Neurophysiological cvidence. Ciba Found. Symp. 91: 206-224.

Holz, G. G., IV, S. G. Rane, and K. Dunlap (1986a) GTP-binding proteins mediate transmitter inhibition of voltage-dependent calcium channels. Nature 319: 670-672.

Holz, G. G., IV, K. Dunlap, and R. M. Kream (1986b) Pertussis toxinsensitive GTP-binding proteins couple alpha-2 and GABA-B receptors to inhibition of neurosecretion in dorsal root ganglion cells. Soc. Neurosci. Abstr. 12: 1195.

Jessell, T. M., and L. L. Iversen (1977) Opiate analgesics inhibit substance $P$ release from rat trigeminal nucleus. Nature 268: 549551.

Kerr, L. M., and D. Yoshikami (1984) A venom peptide with a novel presynaptic blocking action. Nature 308: 282-284.

Kream, R. M., T. A. Schoenfeld, R. Mancuso, A. Clancy, W. El-Bermani, and F. Macrides (1985) Prccursor forms of substance P (SP) in nervous tissue: Detection with antisera to SP, SP-Gly, and SP-GlyLys. Proc. Natl. Acad. Sci. USA 82: 4832-4836.

McCleskey, E. W., A. P. Fox, D. Feldman, B. M. Olivera, R. W. Tsien, and D. Yoshikami (1987) $\omega$-Conotoxin: Direct and persistent blockade of specific types of calcium channels in neurons but not muscle. Proc. Natl. Acad. Sci. USA 84: 4327,4331.

Miller, R. J. (1985) How many types of calcium channels exist in neurons? Trends Neurosci. 80: 45-47.

Miller, R. J. (1987) Multiple calcium channels and neuronal function. Science 235: 46-52.

Mudge, A. W. (1979) Studies on substance P, somatostatin, and enkephalin in cultures of sensory neurons. Ph.D. dissertation thesis, Harvard University, Cambridge, MA.

Mudge, A. W. (1981) Effect of chemical environment on levels of substance $\mathbf{P}$ and somatostatin in cultured sensory neurones. Nature 292: 764-767.

Mudge, A. W., S. E. Leeman, and G. D. Fischbach (1979) Enkephalin inhibits release of substance $P$ from sensory neurons in culture and decreases action potential duration. Proc. Natl. Acad. Sci. USA 76: $526-530$.

Nachshen, D. A., and M. P. Blaustein (1979) The effects of some organic "calcium antagonists" on calcium influx in presynaptic nerve terminals. Mol. Pharmacol. 16: 579-586. 
Nicoll, R. A., C. Schenker, and S. E. Leeman (1980) Substance P as a transmitter candidate. Annu. Rev. Neurosci. 3: 227-268.

Nowycky, M. C., A. P. Fox, and R. W. Tsien (1985a) Three types of neuronal calcium channel with different calcium agonist sensitivity. Nature 316: 440-443.

Nowycky, M. C., A. P. Fox, and R. W. Tsien (1985b) Long-opening mode of gating of neuronal calcium channels and its promotion by the dihydropyridine calcium agonist Bay K 8644. Proc. Natl. Acad. Sci. USA 82: 2178-2182.

Olivera, B. M., J. M. McIntosh, L. J., Cruz, F. A. Luque, and W. R. Gray (1984) Purification and sequence of a presynaptic peptide toxin from Conus geographus venom. Biochemistry 23: 5087-5090.

Otsuka, M., and S. Konishi (1976) Release of substance P-like immunoreactivity from isolated spinal cord of newborn rat. Nature 264 : 83-84.

Payan, D. G., and E. J. Goetzl (1985) Modulation of lymphocyte function by sensory neuropeptides. J. Immunol. 135: 783s-786s.

Perney, T. M., L. D. Hirning, and R. J. Miller (1986) Multiple calcium channels mediate neurotransmitter release from peripheral neurons. Proc. Natl. Acad. Sci. USA 83: 6656-6659.

Pernow, B. (1983a) Substance P. Pharmacol. Rev. 35: 85-141.

Pernow, B. (1983b) Substance $\mathrm{P}-\mathrm{a}$ putative mediator of antidromic vasodilation. Gen. Pharmacol. 14: 13-16.

Pernow, B. (1985) Role of tachykinins in neurogenic inflammation. J. Immunol. 135: 812s-815s.

Rane, S. G., and K. Dunlap (1986) Kinase C activator 1,2-oleoylacetylglycerol attenuates voltage-dependent calcium current in sensory neurons. Proc. Natl. Acad. Sci. USA 83: 184-188.
Rane, S. G., G. G. Holz IV, and K. Dunlap (1987) Dihydropyridine inhibition of neuronal calcium current and substance $P$ release. Pflugers Arch. 409: 361-366.

Reynolds, I. J., J. A. Wagner, S. H. Snyder, S. A. Thayer, B. M. Olivera, and R. J. Miller (1986) Brain voltage-sensitive calcium channel subtypes differentiated by $\omega$-conotoxin fraction GVIA. Proc. Natl. Acad. Sci. USA 83: 8804-8807.

Sanguinetti, M. C., and R. S. Kass (1984) Voltage-dependent block of calcium channel current in the calf cardiac Purkinje fiber by dihydropyridine calcium channel antagonists. Circ. Res. 55: 336-348.

Sanguinetti, M. C., D. S. Krafte, and R. S. Kass (1986) Voltage-dependent modulation of $\mathrm{Ca}$ current in heart cells by Bay $\mathrm{K} 8644$. J. Gen. Physiol. 88: 369-392.

Suszkiw, J. B., M. E. O'Leary, M. M. Murawsky, and T. Wang (1986) Presynaptic calcium channels in rat cortical synaptosomes: Fast-kinetics of phasic calcium influx, channel inactivation, and relationship to nitrendipine receptors. J. Neurosci. 6: 1349-1357.

Takahashi, M., and A. Ogura (1983) Dihydropyridines as potent calcium channel blockers in neuronal cells. FEBS Lett. 152: 191-194.

Toll, L. (1982) High-affinity binding and inhibition of calcium transport in clonal cell line. J. Biol. Chem. 257: 13189-13192.

Turner, T. J., and S. M. Goldin (1985) Calcium channels in rat brain synaptosomes: Identification and pharmacological characterization: High affinity blockade by organic $\mathrm{Ca}$ channel blockers. J. Neurosci. 5: 841-895.

Yaksh, T. L., T. M. Jessell, R. Gamse, A. W. Mudge, and S. E. Leeman (1980) Intrathecal morphine inhibits substance $P$ release from mammalian spinal cord in vivo. Nature 286: 155-157. 